\title{
Coefficient of Friction and Subjective Assessment of Slippery Work Surfaces
}

\author{
ERIC E. SWENSEN, ${ }^{1}$ JERRY L. PURSWELL, ${ }^{2}$ and ROBERT E. SCHLEGEL, University of \\ Oklahoma, Norman, Oklahoma, and RONALD L. STANEVICH, National Institute for \\ Occupational Safety and Health, Morgantown, West Virginia
}

\begin{abstract}
Research was conducted to determine how well subjects could distinguish between surfaces with different coefficient of friction (COF) values and to evaluate how well subjective ratings of slipperiness correlated with the actual COF values. Thirty-three ironworkers experienced in working and walking on steel surfaces and 23 university students inexperienced with these tasks participated in the study. Subjective slipperiness ratings for a variety of climbing and walking conditions were obtained from the subjects. It was found that subjects could identify differences in the slipperiness of four types of steel coatings tested in the study. There was a high correlation between the subjective ratings and the measured COF values. Subjects did not slip at a COF of 0.41 but did lose footing at a COF of 0.20 .
\end{abstract}

\section{INTRODUCTION}

Accidents caused by slips and falls on slippery work surfaces present a significant safety problem. Buck and Coleman (1985) showed that in $1982,14 \%$ of all reported accidents in the manufacturing and construction industries in the United Kingdom were caused by slipping, tripping, or falling. They further pointed out that in a five-year period ending in $1982,40 \%$ to $57 \%$ of all serious or fatal accidents in the mining and quarrying industry were of these types. The problem is one that reaches into all areas of life, including the place of employment, public use areas, and the home environment. This prob-

\footnotetext{
${ }^{1}$ Now at the U.S. Coast Guard Research and Development Center, Groton, Connecticut.

${ }^{2}$ Requests for reprints should be sent to Jerry $L$. Purswell, School of Industrial Engineering, University of Oklahoma, Norman, OK 73019.
}

lem has been important enough to warrant investigation over the last 50 years. Research has concentrated on an objective measure of slip resistance-the coefficient of friction (COF)-on COF measuring devices, and on shoe and floor materials.

The precipitating event leading to a person falling and becoming injured is often a loss of traction between the footwear and the work surface. The traction required by the worker is related to the type of task being performed, the load being handled, the type of gait, and the inclination of the working surface. The traction that must exist in order to avoid slipping is related to the COF that exists between the shoe material and the work surface. A COF measurement of 0.5 has been suggested as the minimum acceptable value when setting safety standards in industry (Miller, 1983). However, differences in COF testing 
methods, material specimens, and work conditions in various industries make it difficult to establish and apply a universal standard.

Brough, Malkin, and Harrison (1979) stated that three principal actions are involved when people slip while walking: (1) the heel may slip forward on making contact with the ground, (2) the toe may slip backward in the action of pushing the body forward or during a turning movement, and (3) slipping may be started during a turning movement from the ball of the outer foot. Using film analysis, they determined the horizontal speeds and positions of the feet throughout the walking process. Although both heel slip and toe slip were observed in their films, they believed that heel slip was of primary concern in slipping accidents.

Harrison and Malkin (1983) provided further evidence of the importance of heel slip by reporting that there were relatively small areas of contact between the shoe sole and the walking surface, especially during the initial heel contact phase. Even when the ball of the foot is in contact with the surface, the contact area does not involve the full width of the shoe sole.

Attempts to simulate slipping have shown that slips do not occur from a static position. Tisserand (1985) showed that a mechanical analysis may suggest that there is no risk of slipping as long as thrust does not exceed the static friction limit. This would suggest that the static COF could be the basis for determining safety limits. However, this does not take into account the differences people have in gait and equilibrium.

In a study of shoe sole slipperiness and structural steel coatings under painted, unpainted, dry, and wet conditions, Irvine (1970) found that differences in the slipperiness of various shoe soles could be distinguished. It was noted that some shoe sole materials demonstrated better nonslip qualities on unpainted steel while it was wet but that the reverse was true when the steel had a painted coating. Irvine concluded that the sole material was more important than the tread design when walking on steel beams or plating. This finding concurs with that of Hopkins (1966) and of Pfauth and Miller (1976).

Many investigators, including Tisserand (1985), Andres and Chaffin (1985), Ballance, Morgan, and Senior (1985), and Perkins and Wilson (1983), have endorsed the measurement of both static and dynamic COF in determining the effective slipperiness of a surface. Because slips occur during walking, the foot is in motion when the shoe comes in contact with the surface. Thus according to these authors, the measurement of dynamic COF would appear to more closely approximate the walking task and environmental conditions than would static COF measurements. Brungraber (1976), however, showed that the most significant parameter controlling the slip resistance of floors was the static COF. He also explained that because of the phenomenon of sticktion on a wet surface, an increase in the measured static COF accompanies an increase in the elapsed time between application of the normal load (placement of a test sled on the test surface) and application of the sliding force. Perkins and Wilson (1983) suggested that the static COF is a better indicator of slipperiness than is the dynamic COF but that the dynamic COF is most appropriate for slippery surfaces when a velocity of $50-100 \mathrm{~cm} / \mathrm{s}$ is involved.

Miller (1983) stated that for walking unloaded on level surfaces, a static COF of 0.5 for the shoe-surface interaction appears to be consensually acceptable as a quantitative standard. It is slightly higher than the minimum COF of 0.4 that initial research had shown was required for walking. The U.S. Federal Trade Commission set a precedent in 
using a static COF value of 0.5 as the dividing line between slippery and slip resistant (Miller, 1983).

In many day-to-day situations a decision must be made by a worker about the hazards of walking on surfaces where slipping and falling are possible. This decision ideally would be made after a COF measurement was completed and some standard for minimum COF was applied. However, this is not the usual situation. In many instances the worker will make a subjective assessment of the slipping hazard by sliding a foot along the surface or walking carefully over a part of the surface. This subjective test may provide an accurate assessment of the hazard of slipping, or it may be inadequate to predict the risk of slipping and falling. Even if the subjective assessment is correct, there may be pressure from the employer to proceed with the work in the absence of some objective assessment of the level of hazard (i.e., COF measurement). The present study was conducted to determine how well workers' subjective evaluations relate to the actual hazard of slipping as indicated by objective COF measurements.

\section{METHODS}

\section{Subjects}

Thirty-four male subjects between the ages of 20 and 60 years (mean $=34.9$ years) and with 0.3 to 35 years of experience (mean = 13.1 years) performed tasks in the first phase of the study. Of this number, 22 were recruited from a pool of available ironworkers who were members of the International Association of Bridge, Structural and Ornamental Ironworkers. All members of the local union were contacted by telephone, screened for back injury or other health problems, and given a summary of the study and pay scheme. All interested volunteers were used. Twelve nonunion steel erectors were also re- cruited to complete this group of experienced ironworkers. Each ironworker was paid his current hourly wage for participating in the study. One subject was unable to perform the climbing task and was dropped from the study. Subject height (mean $=178 \mathrm{~cm}$ ) ranged from 168 to $188 \mathrm{~cm}$ and subject weight (mean $=76.6 \mathrm{~kg}$ ) ranged from 63.5 to $110.7 \mathrm{~kg}$.

In the second phase of the study, 23 graduate and undergraduate students with no ironworking experience were recruited. These subjects were not paid for their participation. Their ages ranged from 20 to 34 years (mean $=24.1$ years). Height $($ mean $=174 \mathrm{~cm}$ ) ranged from 150 to $191 \mathrm{~cm}$ and weight (mean $=67.7 \mathrm{~kg}$ ) ranged from 49.0 to $99.8 \mathrm{~kg}$.

\section{Design}

Subjects performed climbing and walking tasks under a variety of surface conditions. All testing was conducted inside a large building with temperatures ranging from 24 ${ }^{\circ} \mathrm{C}$ to $31^{\circ} \mathrm{C}\left(75^{\circ} \mathrm{F}\right.$ to $\left.88^{\circ} \mathrm{F}\right)$. Four structural steel columns and beams were erected for the first phase of the study. The columns selected for climbing were I-beams (W $12 \times 35$ steel) having a flange width of $16.5 \mathrm{~cm}$ (6.5 in.) and a web depth of $30.4 \mathrm{~cm}$ (12 in.), with a length

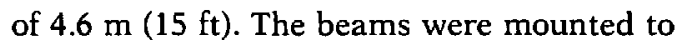
the columns such that the walking surface of the beams was $3.7 \mathrm{~m}(12 \mathrm{ft})$ above the floor. The beams were fabricated from steel plate into an I-beam structural shape. The top and bottom flanges were $15.2 \mathrm{~cm}$ ( 6 in.) wide. The beams were supported on one end by the columns and on the other end by resting on a transverse I-beam, which was placed under the beams. The columns and beams were spaced at $1.2 \mathrm{~m}(4 \mathrm{ft})$ intervals.

The test apparatus for the second phase of the study consisted of the vertical columns from the first phase placed horizontally on the ground with $1.2 \mathrm{~m}(4 \mathrm{ft})$ of separation. The 
height of the walking surface was $0.61 \mathrm{~m}(2 \mathrm{ft})$ above the ground with a total walking distance of $4.6 \mathrm{~m}(15 \mathrm{ft})$.

The steel beams and columns had one of four surface treatments: (1) uncoated (untreated natural mill finish with minimal rust), (2) red zinc alkyd-oxide coating (Anchor Paint Primer \#1722), (3) yellow zinc chromate (Anchor Paint Primer \#1721), or (4) gray zinc-rich coating (Carboline Carbo Zinc11). Except for the untreated column and beam, all surfaces of the columns and the walking surfaces of the beams were sandblasted to remove mill scale and any other contaminants that might prevent the coatings from adhering properly. The coatings were brushed onto the steel following the coating manufacturers' explicit recommendations. The order of presentation of the coatings was counterbalanced across subjects.

Also included as an independent variable were different surface contaminants: water in both studies, clay in the ironworker study, and an oil/plastic sheet combination in the university student study. The dry, clean surface served as a control. Water was applied to the columns and beams in a fine mist using a standard garden sprayer. The clay contaminant was prepared by mixing water with a screened firebrick clay until a homogeneous mixture was obtained. The clay was poured into a large metal tray to a thickness of approximately $1.3 \mathrm{~cm}(1 / 2 \mathrm{in}$.). Subjects stepped into the clay and immediately began climbing the column. Before walking across a beam, subjects stepped into a pile of clay placed at the end of the beam. The oil/plastic sheet combination consisted of a coating of oil applied to a thin plastic sheet that covered the beam. Thus the subjects could not obtain direct contact with the beam coating.

The criterion measures for this study were the following: (1) static COF measurement, (2) subjective rating of the slipperiness of the surface, and (3) subjective ordinal ranking of the coatings according to slipperiness. The primary objective measure in this study was the static COF. To test a subject's ability to discriminate between the different surfaces, a sufficient range of COF values was needed. The range of $C O F$ values presented to the ironworkers was 0.41 to 0.98 . The university students were presented a COF range of 0.20 to 0.98 .

A graphic rating scale similar to the one used by Cushman (1986) for measuring subjective fatigue and performance was used to obtain the subject's evaluation of slipperiness. The subjective scaling method was used to obtain separate ratings for the beam and for the column after each trial. To provide the ratings, subjects placed vertical marks along an 8.9-cm (31/2-in.) horizontal scale, one mark for the beam and one mark for the column, after each trial. The scale was labeled with three cues: SLIPPERY, MID, and NOT SLIPPERY, representing 0, 5, and 10 units, respectively. Each mark was scored on a scale of 0-10 with half-unit increments. A cardboard mask was placed over the scoring sheet to eliminate possible bias from observing previous ratings.

\section{Apparatus}

The instrument used to measure COF was built specifically for this study. A variablespeed motor with a pulley and a $22.7-\mathrm{kg}$ (50lb) test monofilament line was used to provide a horizontal pulling force for a $3.1-\mathrm{kg}$ (6.75-lb) test sled resting on the beam. To the bottom of the test sled was attached a $13.3 \times$ $10.2 \mathrm{~cm}\left(5 \frac{1}{4} \times 4 \mathrm{in}\right.$.) section of the shoe sole material used by the subjects. An aluminum wheel $9.2 \mathrm{~cm}(35 \% \mathrm{in}$.) in diameter and $0.6 \mathrm{~cm}$ ( $1 / 4$ in.) thick, mounted on a 10 -turn potentiometer, trailed the sled to measure its movement. A $22.7-\mathrm{kg}$ load cell between the motor and the sled measured the force required to pull the sled parallel to the test surface.

In operation, the variable-speed motor was 
adjusted to apply a slowly increasing pulling force to the sled to determine static COF, measured as the ratio of the pulling force required for initial sled movement divided by the weight of the sled. To minimize sticktion effects for the wet condition, one experimenter held the sled clear of the beam until the second experimenter controlling the motor was ready. The pulling force was applied immediately upon contact of the sled.

The equipment used to record the COF consisted of a digital weight indicator (AMETEK Series 6000 ), which provided the excitation voltage for the load cell and yielded an analog electrical signal that was proportional to the force applied to the sled. The analog signal was converted by a Transera 8-bit analog-todigital converter connected to a Tektronix (Model 4051) computer. The analog signal was sampled at a rate of 20 points per second. Data (force and velocity) were plotted on the screen and stored for later analysis.

All participants in the study wore their normal work clothes. This typically included a pair of jeans and a T-shirt or cotton work shirt. The ironworkers in the first phase were asked to wear their tool belt and bolt bag. Generally this included two spud wrenches, a bull pin, and a connecting bar. The students in the second phase did not have this added weight. Shoe fit and type was controlled by providing a supply of Red Wing \#2233 safety work shoes with urethane soles. Each subject was able to select his correct shoe size before participating in the study.

\section{Procedure}

Subjects were tested in groups of three or four. Because of the logistics involved in setting up the contaminant conditions, the order of contaminants was fixed. All subjects in the group first encountered the dry condition, then the wet condition, and finally the clay or oil/plastic contamination condition. The columns and beams were thoroughly cleaned and then dried with compressed air before the next group of subjects was tested. Each subject had a break period while others in the group were tested on the four steel structures with the current contaminant. As mentioned previously, the sequence in which the steel structures were climbed was counterbalanced across subjects. The entire test period lasted 1.5 to $2 \mathrm{~h}$ per group of subjects.

The subject attempted to climb a column by placing his boot sole against the inside surface of the flange of the I-beam while grasping the edges of the opposite flange with his hands (Figure 1). Subjects were offered gloves to aid in gripping the column, but all subjects declined the gloves and preferred to climb bare-handed. After climbing to the 3.7-m level, the subject swung onto the beam and attached a safety harness to a lanyard installed on an overhead mobile crane with a track parallel to the beam. The track supported the lanyard as the subject walked (Figure 2). The subject then walked $4.6 \mathrm{~m}$ across the beam, turned, and walked back. He unhooked the lanyard from the harness, swung onto the column, and then slid down the column to complete the test. During the tests some subjects could not climb the columns under certain conditions. When this occurred, these subjects climbed a ladder in order to walk across the beams. After a subject had finished each trial, he was asked to rate

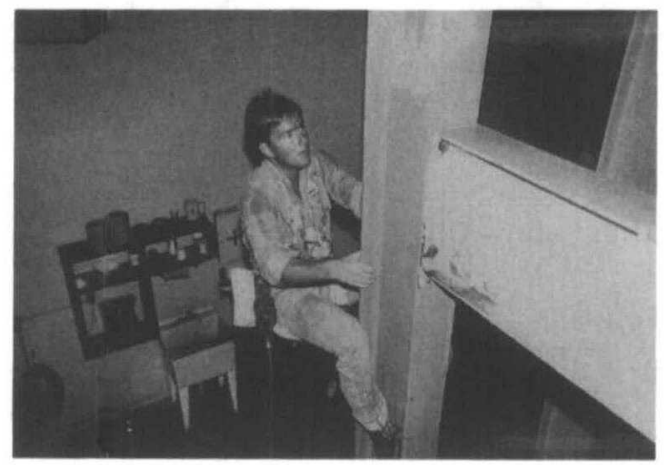

Figure 1. Ironworker climbing a column. 


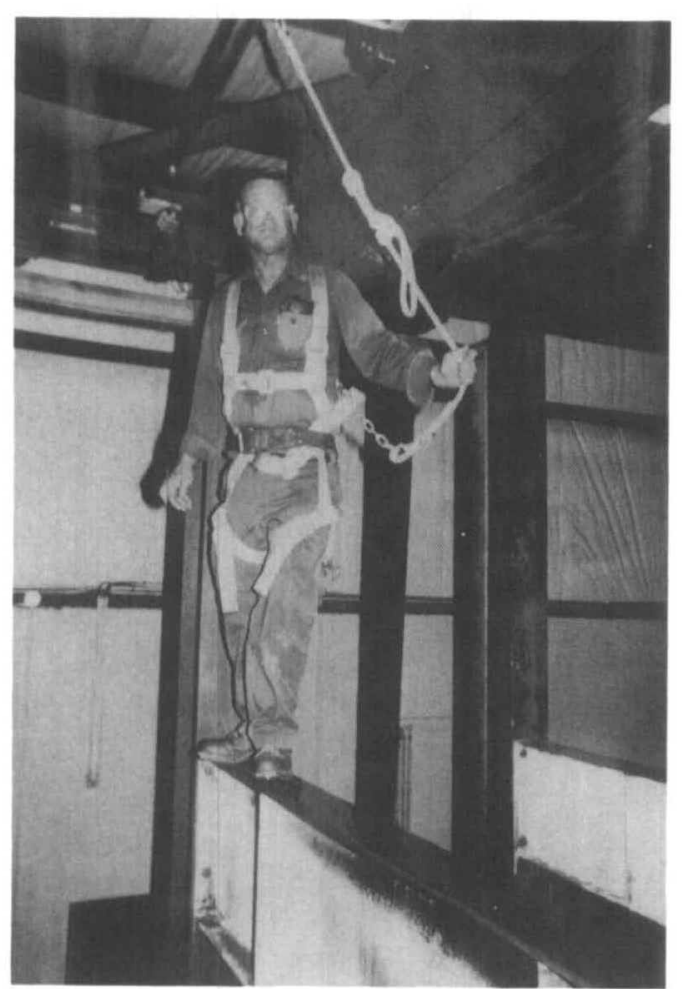

Figure 2. Ironworker with safety hamess walking across a beam.

that column and beam for slipperiness. Separate ratings were allowed for the column and the beam. Each subject rated the slipperiness of both the column and the beam whether or not he was able to successfully climb. At the end of a run (all four beams with a single contaminant), the subject was asked to rank the four coatings from best to worst.

The second phase of the study was conducted in a similar manner. The students were asked to traverse the columns that had been positioned horizontally on the ground. After completing an orientation, the student subjects donned the safety harness, stepped onto the steel member, hooked themselves onto the lanyard, walked the length of the member, turned around, and walked back. The students were then asked for a rating of the surface. At the end of each set of trials with a single contaminant, the students ranked each surface from best to worst.

\section{RESULTS}

The first step in the analysis was to determine if the subjective ratings of slipperiness differentiated surfaces with different COF values. The second step was to determine how well the ratings correlated with the objective COF measurements. A comparison of the two subject groups was also performed.

\section{Objective COF Measurements}

Table 1 presents the static COF measurements obtained for the shoe sole for the various test conditions measured before and after the subject trials. The COF values were generally lower (more slippery) for measurements taken at the conclusion of the experimental trials. A visual examination of the surfaces showed them to be polished after the trials from contact with the shoe soles. The clay contaminant may also have acted as a polishing agent.

Figure 3 shows the mean posttest COF values for the beams. It can be seen that the yellow zinc chromate coating provided the low. est $\mathrm{COF}$ values (mean $=0.45$ ) across the variety of contaminants evaluated (excluding the oil/plastic sheet combination, which consistently provided a COF of 0.20 independent of surface treatment). The gray Carbo Zinc-11 provided the highest values (mean $=0.74$ ) . The uncoated beam and the red zinc alkydoxide provided intermediate COF values of 0.51 and 0.53 , respectively. Interestingly, all of the COF values for the wet contaminant (mean $=0.71$ ) were higher than those for the dry condition (mean $=0.53$ ). Brungraber (1976), Brough et al. (1979), and Harrison and Malkin (1983) found similar increases in COF values from a dry to a wet condition. One explanation for this phenomenon could be that dust or abrasion of the pigment in the dry condition produces a contaminated surface, 
TABLE 1

Static COF Values for Beams under Various Test Conditions

\begin{tabular}{|c|c|c|c|c|c|c|c|}
\hline \multirow[b]{3}{*}{ Coating } & \multicolumn{7}{|c|}{ Contaminant } \\
\hline & \multicolumn{2}{|c|}{ Dry } & \multicolumn{2}{|c|}{ Wet } & \multicolumn{2}{|c|}{ Clay } & \multirow[b]{2}{*}{ OillPlastic } \\
\hline & Pre & Post & Pre & Post & Pre & Post & \\
\hline $\begin{array}{l}\text { Uncoated } \\
\text { Red } \\
\text { Yellow } \\
\text { Gray }\end{array}$ & $\begin{array}{l}0.64 \\
0.79 \\
0.67 \\
0.69\end{array}$ & $\begin{array}{l}0.43 \\
0.49 \\
0.42 \\
0.76\end{array}$ & $\begin{array}{l}0.73 \\
0.85 \\
0.90 \\
0.98\end{array}$ & $\begin{array}{l}0.68 \\
0.68 \\
0.55 \\
0.92\end{array}$ & $\begin{array}{l}0.42 \\
0.41 \\
0.41 \\
0.52\end{array}$ & $\begin{array}{l}0.41 \\
0.42 \\
0.39 \\
0.54\end{array}$ & $\begin{array}{l}0.20 \\
0.20 \\
0.20 \\
0.20\end{array}$ \\
\hline
\end{tabular}

Pre $=$ betore and post $=$ after subject trials.

whereas the wet condition washes away any dust or pigment, thus making the surface less contaminated and more adhesive. This phenomenon has been referred to as sticktion by Andres and Chaffin (1985).

\section{Subjective Responses: Experienced Subjects}

Experienced subjects' subjective ratings for the walking task (beams) are presented in Figure 4. The subjects used a large portion of the rating scale across the various conditions (means ranging from 2.9 to 8.7 ). In terms of coatings, the ratings differed significantly, $F(3,96)=47.05, p<0.0001$, and corresponded well with the information from the COF values. The gray coating, with its average rating of 8.1 , was significantly better than

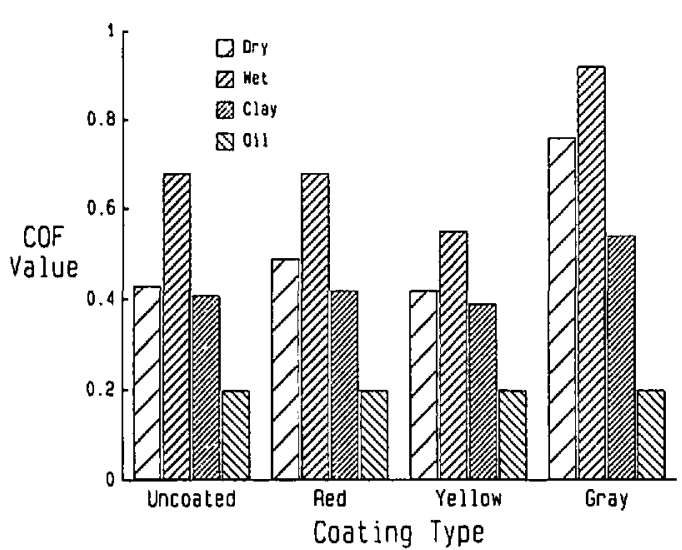

Figure 3. Mean posttest COF values for beams. all others. The yellow coating was worst, with an average rating of 3.5 . The uncoated beam (mean $=4.6$ ) and the red coating (mean $=$ 5.0) were not statistically different.

The surface contaminant also produced significant differences in the ratings, $F(2,64)=$ $10.81, p<0.0001$. Ratings for the clay contaminant (mean $=4.6$ ) were significantly lower than those for the wet (mean $=5.8$ ) or dry (mean $=5.8$ ) conditions, which did not differ significantly. The difference in the ratings by contaminant was expected, given that the slightest amount of clay contaminant would keep a worker from getting a good grip on the surface. The Coating $\times$ Contaminant interaction was significant, $F(6,189)=4.11$, $p=0.001$.

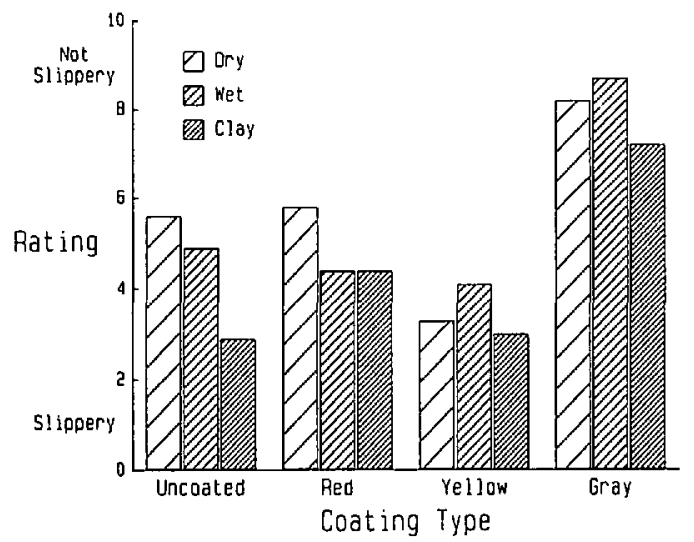

Figure 4. Mean subjective ratings for walking task: experienced subjects. 
Figure 5 presents the subjective ratings for the climbing task (columns). These ratings also differed significantly among the coatings, $F(2,96)=69.52, p<0.0001$, in correspondence with the COF values. The gray coating was significantly better than all others, with an average rating of 5.6. The yellow coating was worst, with an average rating of 0.7 . The uncoated column (mean $=2.5$ ) and the red coating (mean $=2.2$ ) were not statistically different. There were significant differences among the ratings for all three surface conditions, $F(2,64)=106.85, p<0.0001$. The ratings averaged $4.6,2.5$, and 1.1 for the dry, wet, and clay conditions, respectively. The Coating $\times$ Contaminant interaction was significant, $F(6,189)=6.71, p<0.0001$.

With means ranging from 0.2 to 7.5 , the ratings for the climbing task were considerably lower than those for the walking task. This is a good indication of the task differences. In climbing, more force is required to lift the body in a situation in which less force is available. Although the COF may be the same for both activities, the lower force perpendicular to the climbing surface means that less traction is available for climbing compared with the traction required to prevent slipping while walking.

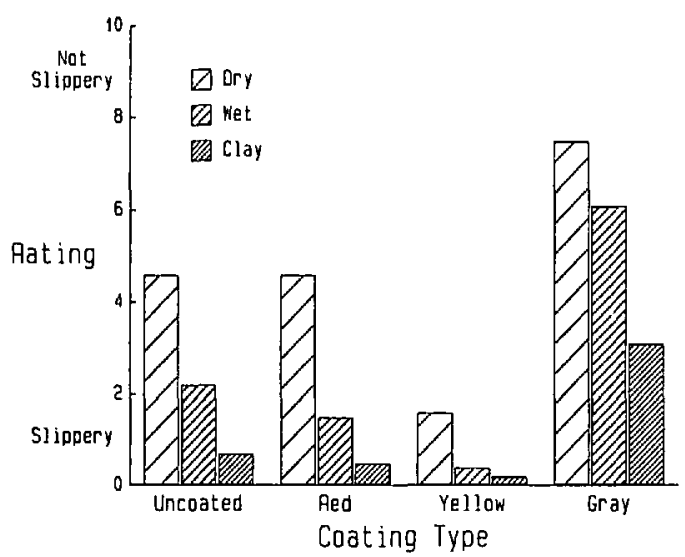

Figure 5. Mean subjective ratings for climbing task: experienced subjects.
The subjective rankings of the coatings confirm the order obtained from the COF and rating data. Subjects consistently ranked the gray coating as providing the best surface for climbing and walking. The yellow coating provided the worst surface for both tasks. With respect to climbing only, the uncoated beam was slightly better than the red coating, especially with the water contaminant.

There was a strong correlation between the subjective ratings for the beams and the subjective ratings for the columns $(r=0.89)$. A reasonable correlation was also obtained between the subjective ratings for the beams and the posttest COF measurements for the beams $(r=0.75)$. This demonstrates a strong association between the subjective ratings and the objective COF values, and it therefore encourages the use of subjective evaluation to assess the safety of working conditions and to indicate the need for objective COF measurement.

\section{Subjective Responses: Inexperienced Subjects}

Figure 6 shows the mean values of the slipperiness ratings (ranging from 1.3 to 7.8 ) for the walking task performed by the inexperienced subjects. There were highly significant differences in the ratings among all three surface contaminants, $F(2,44)=148.72, p<$ 0.0001 . Ratings for the oil contaminant (mean $=1.5$ ) were substantially lower than those for the wet (mean $=5.9$ ) and dry (mean $=7.1$ ) conditions. The ratings differed significantly in terms of coatings, $F(3,66)=9.53$, $p<0.0001$, but had fewer significant differences than those provided by the ironworkers.

Because of a significant Coating $\times$ Contaminant interaction, $F(6,129)=3.46, p=$ 0.0033 , separate analyses were performed for each contaminant. There was no significant difference between coatings for the dry condition, $F(3,85)=2.01, p=0.1180$, or for the 


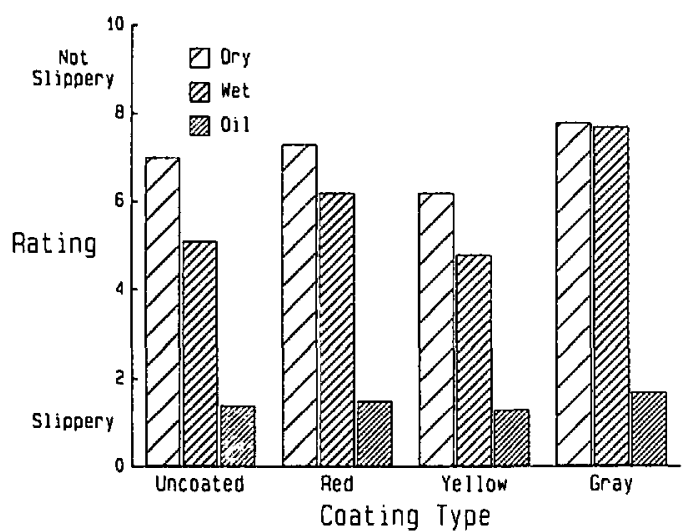

Figure 6. Mean subjective ratings for walking task: inexperienced subjects.

oily contaminant, $F(3,85)=0.16, p=0.9199$. However, the gray coating was significantly better for the water contaminant, $F(3,85)=$ $8.00, p<0.0001$. These results were evident during testing because many of the inexperienced subjects had difficulty in ranking the various surfaces. Many subjects noted that during the dry trials (and certainly during the oil/plastic sheet trials), they could not judge any differences in the four coatings presented.

As with the group of experienced subjects, there was a high correlation between the subjective ratings and the objective COF values $(r$ $=0.90$ ). However, this was not the case between the beam rankings and the COF measurements $(r=-0.14)$. This is most likely attributable to the restricted scale $(1,2,3,4)$ employed for the rankings.

It was of interest to compare the ratings of the two subject groups, given that both groups walked on beams under the dry and wet conditions. There was no significant difference between the groups in terms of ranking the coatings (in descending order, gray, red, uncoated, and yellow). However, there were significant group differences in the numerical ratings of the coatings, $F(1,52)=$ $15.72, p<0.0001$, primarily for the dry con- dition (7.1 for the experienced group vs. 5.9 for the inexperienced group).

None of the experienced ironworkers slipped during any of the trials. The lowest COF encountered by these subjects was 0.41 . The inexperienced subjects were exposed to COF values of 0.20 and did experience slipping. Perkins and Wilson (1983) noted that slipping under normal walking conditions occurred when the surface COF was below 0.30. They noted that for slips to occur on such surfaces, landing speeds of the heel must be greater than $2 \mathrm{~cm} / \mathrm{s}$. The oil surface tested in this study had COF values less than 0.30; according to Perkins and Wilson this would provide a dangerous slip hazard at any foot velocity. Many students compensated for the hazardous situation by shortening the length of their stride, thus producing lower foot velocities and smaller foot shear forces, as the body's center of gravity was better maintained over the balance zone. This act diminishes the likelihood of slipping. When the students were instructed to walk using a normal walking gait, slipping became more evident.

\section{Discussion}

The primary objective of this study was to compare measured COF values for different surfaces with subjective ratings of surface slipperiness. Various surface coatings and contaminants provided a wide range of $\mathrm{COF}$ values. There were significant differences in the subjective ratings and in the rankings based on the type of coating. Subjects could identify a difference in slipperiness for the coatings studied. These findings were consistent across both subject groups.

In comparing the two groups, there was no significant difference in their ability to rank the coatings in a dry or wet situation. Significant group differences did appear in the ratings of the different coatings for the dry condition. Except for the gray coating, the 
ratings provided by the experienced ironworkers were more toward the slippery end of the scale and exhibited greater differences among the coatings than did the ratings provided by the inexperienced students. One may hypothesize that experience contributes significantly to the ability to detect a potential slip situation. These differences between groups did not exist with the ratings for the wet condition.

The strength of the correlation between the COF values and the subjective ratings is sufficient to demonstrate a substantial relationship between the two. However, the limitations of applying correlation analysis to subjective ratings must be acknowledged. The results of this study may not provide sufficient evidence to show that the subjective method is a total substitute for actual COF measurement. Rather, low ratings would indicate that a dangerous situation existed and that actual COF measurement should be performed.

The final aspect of this research was to estimate a threshold at which subjects are likely to slip while walking or climbing on a surface. Determining a threshold for climbing may prove difficult, given that a vertical climb requires forces acting in opposition to gravity. The climber must possess enough strength and obtain sufficient traction to overcome the pull of gravity. However, this research does support threshold values for walking. Experienced subjects did not slip with COF values of 0.41 . However, inexperienced subjects tested at a COF value of 0.20 did show considerable slipping. These subjects adjusted their walking gaits to smaller steps. Miller (1983) indicated that for walking unloaded, COF values of 0.20 to 0.30 were suitable to use as threshold guides for protecting against slip accidents. The data presented here are inconsistent with those lower limits, at least for this task. The implication from this research is that the COF threshold for loss of footing in this particular activity is below 0.40 but above 0.20 .

This research did not focus on the biomechanical modeling of the slipping process, but it was noted that subjects did adjust their walking gait, to take smaller steps than normal, as they walked on the oil/plastic surface. Future research should investigate this process to isolate the difference in static and dynamic COF for various surfaces. If there is a significant difference, a range of velocities should be investigated to establish specific velocities for measuring dynamic COF. Future efforts in this area should consider the importance of adopting dynamic COF measures in current standards. Suggestions for further research would also include the need to better isolate the threshold COF value that leads to a loss of footing and possible accident. Future accident investigation should document objective COF values present when a fall accident is noted. This would also indicate the need for an easy-to-use and portable COF device that could be used in the field.

\section{ACKNOWLEDGMENTS}

The authors would like to thank Benjamin J. Wallace of the University of Oklahoma Fears Structural Laboratory for his help with this research. Funds for the ironworker phase of the research were provided by the National Institute for Occupational Safety and Health under CDC Contract 200-86-2929.

\section{REFERENCES}

Andres, R. O., and Chaffin, D. B. (1985). Ergonomic analysis of slip-resistance measurement devices. Ergonomics, 28, 1065-1079.

Ballance, P. E., Morgan, J., and Senior, D. (1985). Operational experience with a portable friction testing device in university buildings. Ergonomics, 28, 10431054.

Brough, R., Malkin, F., and Harrison, R. (1979). Measurement of the coefficient of friction of floors. Joumal of Physics D: Applied Physics, 12, 517-528.

Brungraber, R. J. (1976). An overview of floor slip-resistance research with annotated bibliography (NBS Technical Note 895). Washington, DC: National Bureau of Standards.

Buck, P. C., and Coleman, V. P. (1985). Slipping, tripping 
and falling accidents at work: A national picture. Ergonomics, 28, 949-958.

Cushman, W. H. (1986). Reading from microfiche, a VDT, and the printed page: Subjective fatigue and performance. Human Factors, 28, 63-73.

Harrison, R., and Malkin, F. (1983). On-site testing of shoe and floor combinations. Ergonomics, 26, 101-108.

Hopkins, S. K. (1966). Elusive factor in falls: The shoe sole. National Safety News, 94(5), 34-37.

Irvine, C. H. (1970). Shoe sole slipperiness on structural steel. Materials Research and Standards, 10(4), 21-22.

Miller, J. M. (1983). "Slippery" work surfaces: Towards a performance definition and quantitative coefficient of friction criteria. Joumal of Safety Research, 14, 145158.

Perkins, P. J., and Wilson, M. P. (1983). Slip resistance testing of shoes-New developments. Ergonomics, 26, 7382.

Pfauth, M. J., and Miller, J. M. (1976). Work surface friction coefficients: A survey of relevant factors and measurement methodology. Joumal of Safety Research, 8, 77-90.

Tisserand, M. (1985). Progress in the prevention of falls caused by slipping. Ergonomics, 28, 1027-1042. 
